\title{
Uso de vinhaça de alambique e nitrogênio em cana-de-açúcar irrigada e não irrigada
}

\author{
Ednaldo Liberato de Oliveira(1), Luiz Antônio de Bastos Andrade(2), Manoel Alves de Faria(2), \\ Adão Wagner Pêgo Evangelista ${ }^{(3)}$ e Augusto Ramalho de Morais ${ }^{(2)}$
}

\begin{abstract}
(1)Instituto Federal do Norte de Minas, Campus Araçuaí. BR 36, Km 278, CEP 39.600-000 Araçuaí, MG. E-mail: ednaldoliberato@yahoo.com.br (2)Universidade Federal de Lavras, Campus Universitário, Caixa Postal 3037, CEP 37200-000 Lavras, MG. E-mail: laba@ufla.br, mafaria@ufla.br, armorais@ufla.br (3)Universidade Federal de Goiás, Campus II, Caixa Postal 131, CEP $74001-970$ Goiânia, GO. E-mail: awpego@bol.com.br
\end{abstract}

\begin{abstract}
Resumo - O objetivo desse trabalho foi avaliar o efeito da aplicação de vinhaça de alambique, com e sem complementação nitrogenada, em cana-de-açúcar irrigada e não irrigada. O delineamento experimental foi o de blocos ao acaso, em esquema fatorial $4 \times 2$, com três repetições. Os tratamentos corresponderam à aplicação

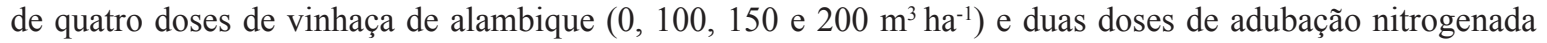
(0 e $60 \mathrm{~kg} \mathrm{ha}^{-1}$ de $\mathrm{N}$ ). As doses estimadas de 142 e $174 \mathrm{~m}^{3} \mathrm{ha}^{-1}$ de vinhaça de alambique proporcionaram as maiores produtividades de colmos para a cana de terceiro corte com e sem irrigação, respectivamente. Na cana de quarto corte, tanto na área com irrigação quanto na sem irrigação houve aumento na produtividade de colmo com o aumento na dose de vinhaça. O conteúdo da fibra da cana foi reduzido com o aumento das doses de vinhaça. Há necessidade da aplicação de nitrogênio em áreas de aplicação de vinhaça com ou sem irrigação. O aumento na produtividade final de colmo com irrigação foi de $15 \%$ no terceiro corte e de $24 \%$ no quarto corte, sendo tecnicamente viável o uso da irrigação em cana soca.
\end{abstract}

Termos para indexação: Saccharum sp., adubação fluída, adubação nitrogenada, cana-soca, irrigação.

\section{Use of pot still vinasse and nitrogen in irrigated and unirrigated sugar cane}

\begin{abstract}
The objective of this work was to evaluate the effect of pot still vinasse on irrigated and unirrigated ratoon cane, with and without addition of nitrogen. The experiment was in a randomized block design in a $4 \times 2$ factorial arrangement, with three replicates. The treatments were four doses of vinasse $(0,100,150$, and $\left.200 \mathrm{~m}^{3} \mathrm{ha}^{-1}\right)$ and two doses of nitrogen fertilizer $\left(0\right.$ and $60 \mathrm{~kg} \mathrm{ha}^{-1}$ of $\left.\mathrm{N}\right)$. Estimated doses of 142 and $174 \mathrm{~m}^{3} \mathrm{ha}^{-1}$ of pot still vinasse provided the highest stalk yield for the third cut, respectively for irrigated and unirrigated conditions. In the fourth cut cane, with and without irrigation, stalk productivity increased with higher vinasse doses. Fiber cane contents decreased with the increase of vinasse doses. Addition of nitrogen is necessary for irrigated and unirrigated sugar cane, when vinasse is used. The final stalk yield increase with irrigation was $15 \%$ for the third cut and $24 \%$ for the fourth cut showing that irrigation of ratoon cane is viable.
\end{abstract}

Index terms: Saccharum sp., flowed fertilization, nitrogen fertilization, ratoon sugar cane, irrigation.

\section{Introdução}

A cadeia produtiva da cachaça de alambique é uma das mais promissoras no desenvolvimento agroindustrial do Brasil. Na produção de cachaça artesanal, se destaca o estado de Minas Gerais, com aproximadamente 8.466 alambiques e uma produção de cachaça de cerca de 220 milhões de litros por ano, movimentando $\mathrm{R} \$ 1,5$ bilhão só com o mercado interno, e gerando cerca de 240 mil empregos. Entretanto, para cada litro de cachaça produzido são produzidos de 8 a 10 litros de vinhaça. Além dos consideráveis teores de nutrientes inorgânicos, este resíduo tem elevado teor de matéria orgânica, que requer grande quantidade de oxigênio ambiental para sua degradação. $\mathrm{O}$ uso como fertilizante das vinhaças de alambique e da produção de álcool, é uma alternativa vantajosa de retorno dos nutrientes para as lavouras quando aplicadas técnicas agrícolas adequadas.

De maneira geral, a vinhaça de alambique apresenta elevadas concentrações de matéria orgânica, potássio e ferro e pequenas proporções de outros macro e micronutrientes. Portanto, sua utilização favorece a reposição de elementos essenciais para as plantas. Entretanto, não existem, até o momento, informações seguras sobre a dose da vinhaça de alambique necessária 
para a substituição parcial ou total da adubação química nos canaviais. Vários autores (Nogueira \& Venturini Filho, 2005; Siqueira, 2008) encontraram uma grande variação na concentração dos componentes da vinhaça: 19 a $50 \%$ de matéria orgânica (MO); 0,028 a $0,9 \mathrm{~kg} \mathrm{~m}^{-3}$ de $\mathrm{N} ; 0,02$ a $0,14 \mathrm{~kg} \mathrm{~m}^{-3}$ de $\mathrm{P}_{2} \mathrm{O}_{5} ; 0,85$ a $4,6 \mathrm{~kg} \mathrm{~m}^{-3}$ de $\mathrm{K}_{2} \mathrm{O} ; 0,46$ a $2,02 \mathrm{~kg} \mathrm{~m}^{-3}$ de $\mathrm{CaO}$ e 0,04 a $0,7 \mathrm{~kg} \mathrm{~m}^{-3}$ de $\mathrm{MgO}$. Assim, o emprego da vinhaça como fertilizante deve ser realizado com cautela, principalmente levando em consideração sua origem, não sendo recomendada uma dose fixa de aplicação.

Para o Conselho de Política Ambiental de Minas Gerais, as dosagens de vinhaça a serem aplicadas no solo devem ser de no máximo $150 \mathrm{~m}^{3} \mathrm{ha}^{-1}$ (mosto de melaço); $300 \mathrm{~m}^{3} \mathrm{ha}^{-1}$ (mosto misto) e $450 \mathrm{~m}^{3} \mathrm{ha}^{-1}$ (mosto de caldo). A norma determina que a aplicação de vinhaça em taxas iguais ou superiores às definidas deverá ser precedida de estudos técnicos (Minas Gerais, 1987). Trabalhos pioneiros sobre utilização de vinhaça erram ao recomendar a aplicação de quantidades excessivas no solo, chegando a recomendar doses entre 500 a $1.000 \mathrm{~m}^{3}$ ha ${ }^{-1}$ de vinhaça (Freire \& Cortez, 2000). A aplicação sem critérios pode causar um desequilíbrio de nutrientes e gerar resultados diferentes dos esperados.

A irrigação da cana-de-açúcar tem sido bastante questionada, tanto pela incerteza na resposta da planta, quanto pelos custos da mesma (Dantas Neto et al., 2006). Estes autores afirmam que, no Brasil, as novas tecnologias de irrigação são significativamente mais baratas que no passado, o que permite a evolução e uso dessa tecnologia no país. Entretanto, o aumento da produção e o retorno econômico da irrigação dependem da região.

A maioria dos trabalhos com adubação nitrogenada em cana-de-açúcar, concluem que a cana-planta não responde ao nitrogênio. Korndorfer et al. (1999) afirmam que não há necessidade de aplicar nitrogênio no plantio da cana-de-açúcar e que a adubação de cobertura com esse nutriente deverá basear-se no histórico da área.

O objetivo deste trabalho foi avaliar os efeitos da aplicação de diferentes doses de vinhaça de alambique, complementadas ou não com nitrogênio, na produção de colmos e nas características tecnológicas da cana-de-açúcar, em ambiente irrigado e não irrigado.

\section{Material e Métodos}

O experimento foi realizado entre setembro de 2006 e setembro de 2008, em área localizada na Cachaçaria
João Mendes (JM), no município de Perdões, na região de campos das vertentes do Estado de Minas Gerais, nas coordenadas $21^{\circ} 03^{\prime} \mathrm{S}$ e $45^{\circ} 00^{\prime} \mathrm{W}$, e altitude média de $826 \mathrm{~m}$. O clima da região, segundo a classificação de Köppen, é do tipo Cwb, caracterizado por uma estação seca entre abril e setembro e uma estação chuvosa de outubro a março. A região apresenta uma média anual de precipitação de $1.493 \mathrm{~mm}$ e temperatura média de $19,3^{\circ} \mathrm{C}$. O solo em que foi instalado o experimento é classificado como Latossolo Vermelho-Amarelo distrófico, textura argilosa, que apresentou na camada de 0-20 cm, antes da instalação do experimento: $\mathrm{pH}\left(\mathrm{CaCl}_{2}\right)$ 5,2; $\mathrm{P}, 0,9 \mathrm{mg} \mathrm{dm}^{-3} ; \mathrm{K}, 23 \mathrm{mg} \mathrm{dm}^{-3} ; \mathrm{Ca}$, $1 \mathrm{cmol}_{\mathrm{c}} \mathrm{dm}^{-3} ; \mathrm{Mg}, 0,4 \mathrm{cmol}_{\mathrm{c}} \mathrm{dm}^{-3}$; CTC, $4,7 \mathrm{cmol}_{\mathrm{c}} \mathrm{dm}^{-3}$; V (\%), 31,5 e uma composição em areia, silte e argila de 410, 160 e $430 \mathrm{~g} \mathrm{~kg}^{-1}$, respectivamente.

$\mathrm{O}$ experimento foi instalado em área plantada com a cultivar de cana-de-açúcar SP80-1816 e, para a análise, foram considerados quatro ambientes: com irrigação (áreas adjacentes), terceiro e quarto cortes (Ci3 e Ci4); e sem irrigação, terceiro e quarto cortes ( $\mathrm{Si} 3$ e $\mathrm{Si} 4$ ).

O delineamento experimental foi o de blocos ao acaso com três repetições, com os tratamentos dispostos em esquema fatorial $4 \times 2$, com quatro doses de vinhaça de alambique $\left(0,100,150\right.$ e $\left.200 \mathrm{~m}^{3} \mathrm{ha}^{-1}\right)$ e duas doses de nitrogênio ( 0 e $60 \mathrm{~kg} \mathrm{ha}^{-1}$ ). Os tratamentos foram aplicados em cobertura, após brotação da soqueira, em dosagem única sobre o palhiço remanescente da cana soca, em outubro de 2006 e agosto de 2007. As doses de vinhaça foram aplicadas com um mangote acoplado a um tanque tracionado por trator. A adubação nitrogenada, com sulfato de amônio, foi feita de forma manual logo após a aplicação da vinhaça. Cada parcela experimental foi composta de cinco linhas de cana de açúcar com 14,3 m de comprimento, espaçadas 1,4 m entre si, ocupando área de $100,10 \mathrm{~m}^{2}$; como área útil foram consideradas as três linhas centrais, totalizando $60,06 \mathrm{~m}^{2}$. As parcelas foram delimitadas por estacas de madeira e separadas por carreadores transversais de 1,00 m de largura. Entre os blocos, foram deixados carreadores de 2,80 $\mathrm{m}$ de largura, para facilitar o trânsito de máquinas e implementos.

A irrigação foi realizada com aspersores de média pressão $(300 \mathrm{kPa})$, instalados no espaçamento 30x24 $\mathrm{m}$, com funcionamento setorial. A primeira irrigação foi realizada em 13/9/2006, elevando-se a umidade do solo na camada de $0 \mathrm{a} 40 \mathrm{~cm}$ à capacidade de campo. A partir daí, a irrigação foi feita com turno de rega fixo 
de sete dias e a reposição da lâmina de irrigação com base na evapotranspiração do período estimada a partir dos dados de evaporação obtidos em tanque classe A, medida diariamente no local.

Para o cálculo da lâmina bruta de irrigação estimouse a evapotranspiração da cana-de-açúcar com base na evaporação acumulada obtida no tanque classe A, levando-se em conta os coeficientes de tanque e de cultura utilizados por Dantas Neto et al. (2006), considerando-se a eficiência de irrigação igual a 0,75. Para isto, foram coletados dados diários de precipitação e evaporação. A irrigação foi cortada 45 dias antes do início de cada colheita.

As lâminas de água totais aplicadas e as precipitações ocorridas ao longo de cada ciclo da cultura da cana-de-açúcar estão apresentadas na Figura 1. Na safra 2006/2007, foram realizadas 17 irrigações e o total de água aplicada à cultura foi de $454,51 \mathrm{~mm}$, com precipitação de 1.041,54 mm. Na safra 2007/2008, foram realizadas 22 irrigações, totalizando uma lâmina de $503,74 \mathrm{~mm}$, com precipitação no período de $1.207,42 \mathrm{~mm}$.

A composição química média da vinhaça de alambique aplicada nas áreas experimentais das soqueiras em outubro de 2006 e em agosto de 2007 foi: $\mathrm{pH}, 3,30$ e 3,50; matéria orgânica (\%), 16,21 e 21,72; $\mathrm{N}\left(\mathrm{kg} \mathrm{m}^{-3}\right), 0,23$ e 0,$33 ; \mathrm{P}_{2} \mathrm{O}_{5}\left(\mathrm{~kg} \mathrm{~m}^{-3}\right), 0,07$ e 0,20 ; $\mathrm{K}_{2} \mathrm{O}\left(\mathrm{kg} \mathrm{m}^{-3}\right), 0,73$ e 0,$88 ; \mathrm{CaO}\left(\mathrm{kg} \mathrm{m}^{-3}\right), 0,14$ e 0,13 ; $\mathrm{MgO}\left(\mathrm{kg} \mathrm{m}^{-3}\right), 0,14$ e 0,$13 ; \mathrm{SO}_{4}\left(\mathrm{~kg} \mathrm{~m}^{-3}\right), 0,33$ e 0,35 ; Fe (ppm), 24 e 22; Zn (ppm), 2,4 e 3,9; Mn (ppm), 0,9 e 0,9 e $\mathrm{Cu}(\mathrm{ppm}), 1,7$ e 0,6 . Observa-se que essa composição apresenta alto conteúdo de $\mathrm{K}$ e de matéria orgânica, quantidades médias de $\mathrm{N}, \mathrm{Ca}, \mathrm{Mg}$ e $\mathrm{S}$, além de conter micronutrientes. A composição química da

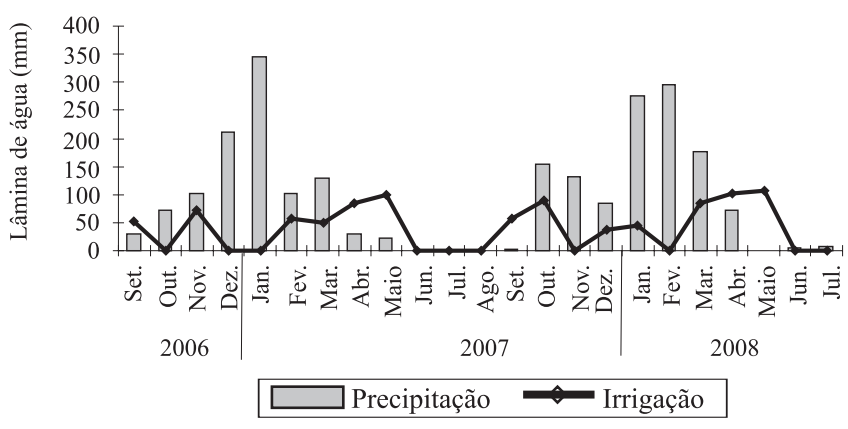

Figura 1. Precipitação mensal e lâmina de água aplicada por irrigação na cultura da cana-de-açúcar entre setembro de 2006 e julho de 2008. vinhaça foi variável em razão da época, safra e ano (Paulino et al., 2002).

A avaliação do experimento foi realizada nas safras 2006/2007 (segunda soca - terceira colheita) e 2007/2008 (terceira soca - quarta colheita), com cortes, respectivamente, em julho de 2007 e 2008. A produtividade de colmos foi obtida por pesagens em balança tipo dinamômetro, com capacidade para $120 \mathrm{~kg}$. Posteriormente, realizou-se a transformação do peso de colmos da área útil da parcela, em toneladas de colmos por hectare $\left(\mathrm{Mg} \mathrm{ha}^{-1}\right)$.

Para avaliação das características tecnológicas da cana-de-açúcar, durante a colheita foram retirados, aleatoriamente, 15 colmos seguidos na área útil de cada parcela, eliminando-se o palmito e a palha. Após identificação, os colmos foram enfeixados, e enviados para o Laboratório da Destilaria Alvorada do Bebedouro Ltda, em Guaranésia, Minas Gerais, para determinação do Brix (\%), sacarose (\%), fibra (\%), pureza (\%), açúcares redutores AR (\%) e açúcares totais recuperáveis (ATR, $\mathrm{kg} \mathrm{Mg}^{-1}$ ), medidos em relação à composição dos colmos.

Os dados foram submetidos à análise de variância de acordo com esquema adequado de análise conjunta para experimentos fatoriais (Gomes, 2000) e as fontes de variação foram: ambientes (A), bloco dentro de $\mathrm{A}$, doses de vinhaça $(V)$, doses de nitrogênio $(\mathrm{N})$, e as interações $\mathrm{V} x \mathrm{~N}, \mathrm{~A} \times \mathrm{V}, \mathrm{A} \times \mathrm{N}, \mathrm{A} \times \mathrm{V} \times \mathrm{N}$. Quando houve efeito significativo das doses de vinhaça e de $\mathrm{N}$ aplicadas utilizou-se a análise de regressão para expressar seus efeitos e, para comparação dos ambientes, utilizou-se o teste de Tukey, a 5\% de probabilidade.

\section{Resultados e Discussão}

A análise conjunta de variância realizada para produtividade de colmos, em função das diferentes doses de vinhaça e nitrogênio, aplicadas nos diferentes ambientes, evidenciou efeitos significativos para os ambientes $(p<0,01)$, doses de vinhaça $(p<0,01)$, e das interações entre doses de vinhaça $x$ nitrogênio $(p<0,01)$ e ambiente $x$ doses de vinhaça $(\mathrm{p}<0,05)$.

Com a aplicação de $60 \mathrm{~kg} \mathrm{ha}^{-1}$ de nitrogênio, constatou-se efeito quadrático das doses da vinhaça sobre a produtividade de colmos, sendo que a dose $166,6 \mathrm{~m}^{3} \mathrm{ha}^{-1}$ de vinhaça proporcionou maior produtividade de colmos (79,2 $\mathrm{Mg} \mathrm{ha}^{-1}$ ) (Figura 2). 
$\mathrm{Na}$ aplicação da vinhaça sem complementação nitrogenada, verificou-se efeito linear significativo das doses de vinhaça, sendo que para cada $1 \mathrm{~m}^{3}$ ha-1 de vinhaça aplicado, observou-se um incremento médio de $77,8 \mathrm{~kg} \mathrm{ha}^{-1}$ (Figura 2).

Os resultados obtidos neste trabalho, com relação à complementação da dose de vinhaça com adubação nitrogenada, são contrários aos obtidos por Trivelin et al. (1995), que não encontraram diferença significativa na produtividade da cana-de-açúcar adubada com vinhaça, complementada com nitrogênio. Entretanto, Rodrigues et al. (1984) afirmam que há aumento na produtividade de colmos com o uso de adubação nitrogenada como complemento da vinhaça. Resende et al. (2006) também encontraram aumento da produtividade da cana-de-açúcar com aplicação de $\mathrm{N}\left(80 \mathrm{~kg} \mathrm{ha}^{-1}\right)$ e vinhaça $\left(80 \mathrm{~m}^{3} \mathrm{ha}^{-1}\right)$, em experimentos conduzidos por nove anos, em Pernambuco.

Quanto à interação ambiente $\mathrm{x}$ vinhaça, no terceiro corte verificou-se efeito quadrático das doses de vinhaça, tanto nos ambientes irrigados quanto nos não irrigados, e no quarto corte observou-se efeito linear (Figura 3). A máxima produtividade estimada, $93,29 \mathrm{Mg} \mathrm{ha}^{-1}$ foi obtida com a dose de 141,66 $\mathrm{m}^{3} \mathrm{ha}^{-1}$ de vinhaça no terceiro corte do ambiente irrigado. No entanto, nesse mesmo corte na área não irrigada, a maior produtividade de colmo foi de 77,43 Mg ha-1 com a dose de $174 \mathrm{~m}^{3} \mathrm{ha}^{-1}$ de vinhaça. No quarto corte, observou-se aumento médio de produtividade de $87,9 \mathrm{~kg} \mathrm{ha}^{-1}$ para cada $1 \mathrm{~m}^{3}$ de vinhaça aplicada no ambiente não irrigado e de $177,9 \mathrm{~kg} \mathrm{ha}^{-1}$ no irrigado.

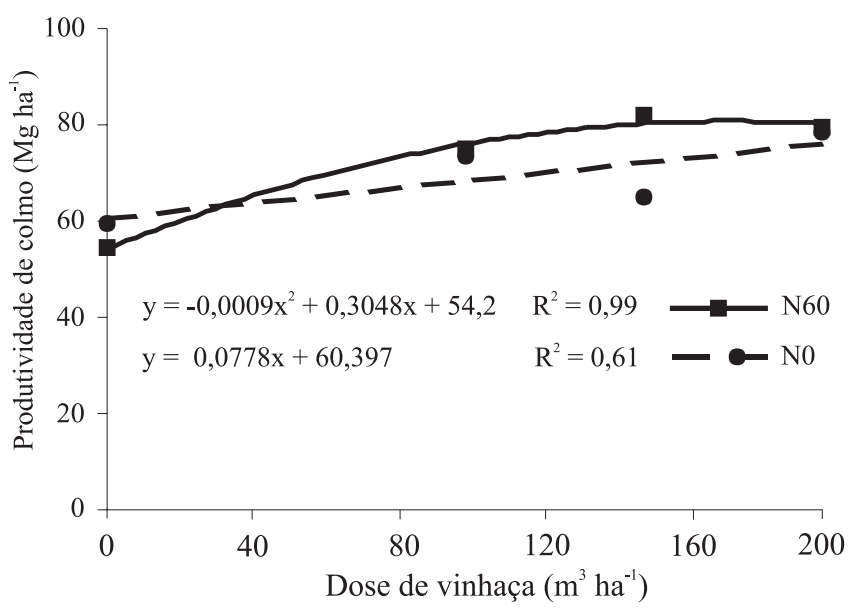

Figura 2. Produtividade de colmo, em cana soca de terceiro e quarto corte, sem nitrogênio (N0) e com $60 \mathrm{~kg} \mathrm{ha}^{-1}$ (N60).
Ao se analisar os efeitos da irrigação sobre a produtividade de colmos, observa-se que, no ambiente irrigado, no terceiro corte, a produtividade média de colmos foi de $84,78 \mathrm{Mg} \mathrm{ha}^{-1}$, correspondente a um acréscimo de $15,16 \%$ em relação à cana não irrigada $(73,62)$ (Tabela 1). No quarto corte, a produtividade média de colmos foi de $68,84 \mathrm{Mg} \mathrm{ha}^{-1}$, correspondente a um acréscimo de $23,65 \%$ em relação à cana não irrigada $\left(55,68 \mathrm{Mg} \mathrm{ha}^{-1}\right)$. Resultados semelhantes foram reportados por Santos (2006) eFarias et al. (2008) que constataram aumento na produtividade de colmos, do ambiente não irrigado para o irrigado, da ordem de $19,21 \%$ e $22,1 \%$, respectivamente.

$\mathrm{O}$ aumento na produtividade de colmo foi maior na cana de quarto corte. Isso provavelmente ocorreu por que, na cana de terceiro corte, a precipitação nos

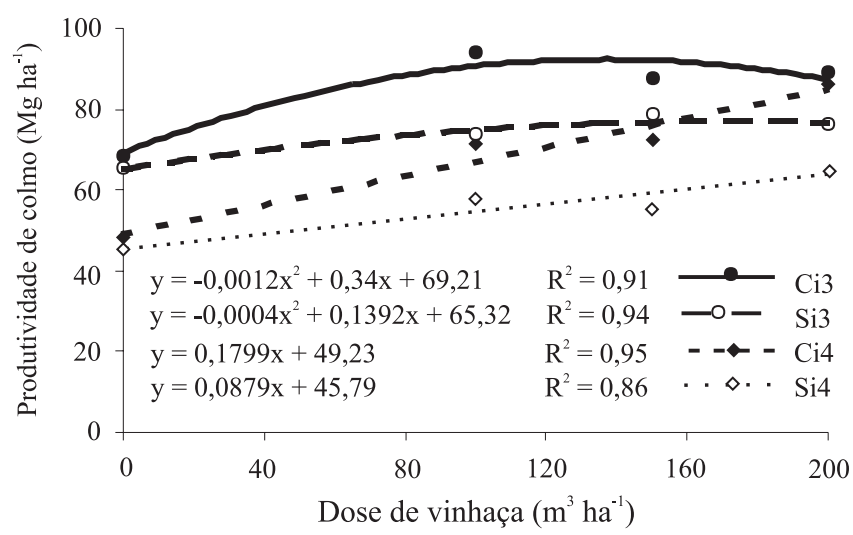

Figura 3. Estimativa da produtividade de colmo na canasoca, submetida a diferentes doses de vinhaça de alambique com irrigação, terceiro e quarto cortes (Ci3 e Ci4), e sem irrigação, terceiro e quarto cortes ( $\mathrm{Si} 3$ e $\mathrm{Si} 4)$.

Tabela 1. Produtividade de colmos $\left(\mathrm{Mg} \mathrm{ha}^{-1}\right)$ com aplicação de vinhaça de alambique e adubação nitrogenada em ambiente irrigado, no terceiro e quarto cortes ( $\mathrm{Ci} 3$ e $\mathrm{Ci} 4$ ), e em ambiente não irrigado ( $\mathrm{Si3}$ e $\mathrm{Si} 4)$.

\begin{tabular}{|c|c|c|c|c|c|}
\hline \multirow{2}{*}{$\begin{array}{l}\text { Vinhaça } \\
\left(\mathrm{m}^{3} \mathrm{ha}^{-1}\right)\end{array}$} & \multirow{2}{*}{$\begin{array}{c}\mathrm{N} \\
\left(\mathrm{kg} \mathrm{ha}^{-1}\right)\end{array}$} & \multicolumn{4}{|c|}{ Ambiente } \\
\hline & & $\mathrm{Ci} 3$ & Si3 & $\mathrm{Ci} 4$ & $\mathrm{Si} 4$ \\
\hline 0 & 0 & $72,52 \mathrm{a}$ & $68,41 \mathrm{ab}$ & $52,04 b c$ & $44,59 \mathrm{c}$ \\
\hline 100 & 0 & $94,49 \mathrm{a}$ & $72,59 \mathrm{~b}$ & $76,76 a b$ & $50,89 \mathrm{c}$ \\
\hline 150 & 0 & $73,48 \mathrm{a}$ & $69,43 \mathrm{a}$ & $71,77 \mathrm{a}$ & $45,68 \mathrm{~b}$ \\
\hline 200 & 0 & $86,35 \mathrm{a}$ & $81,03 \mathrm{ab}$ & $83,24 a b$ & $63,15 c$ \\
\hline 0 & 60 & $64,79 \mathrm{a}$ & $62,66 \mathrm{ab}$ & $44,18 \mathrm{ab}$ & $45,93 \mathrm{~b}$ \\
\hline 100 & 60 & $93,62 \mathrm{a}$ & $75,08 \mathrm{ab}$ & $61,13 b$ & $64,40 \mathrm{~b}$ \\
\hline 150 & 60 & $101,87 \mathrm{a}$ & $88,28 \mathrm{ab}$ & $72,71 b c$ & $64,25 \mathrm{c}$ \\
\hline 200 & 60 & $91,12 \mathrm{a}$ & $71,48 \mathrm{ab}$ & $88,89 \mathrm{a}$ & $66,53 \mathrm{~b}$ \\
\hline Média & & $84,78 \mathrm{a}$ & $73,62 b$ & $68,84 \mathrm{~b}$ & $55,68 \mathrm{c}$ \\
\hline
\end{tabular}

${ }^{(1)}$ Médias seguidas por letras iguais, nas linhas, não diferem entre si pelo teste $\mathrm{t}$, a $5 \%$ de probabilidade. 
primeiros 60 dias após aplicação dos tratamentos foi mais favorável à brotação inicial.

O maior valor obtido no experimento, de $101,87 \mathrm{Mg} \mathrm{ha}^{-1}$ (Tabela 1), no ambiente irrigado, está coerente com Doorenbos \& Kassan (1979), que consideramcomoboa, emáreasirrigadas, produtividades acima de $100 \mathrm{Mg} \mathrm{ha}^{-1}$. Matioli \& Barcelos (1999) verificaram que a irrigação complementar proporciona aumento de produtividade de até $30,4 \mathrm{Mg} \mathrm{ha}^{-1}$ para cana-soca, e Farias et al. (2008) observou diferença significativa de $28,26 \mathrm{Mg} \mathrm{ha}^{-1}$, entre a cana irrigada e a cana de sequeiro.

A análise conjunta de variância realizada para as características tecnológicas da cana-de-açúcar, em função das diferentes doses de vinhaça e nitrogênio aplicadas, nos diferentes ambientes, apontou efeito significativo do ambiente para todas elas. Entretanto, com aplicação de vinhaça, o efeito foi significativo apenas para o teor de fibra.

Os valores médios obtidos para as características tecnológicas, em cada ambiente, estão apresentados na Tabela 2. De modo geral, no ambiente irrigado, no terceiro corte, observou-se a menor qualidade da cana, com baixos teores de Brix, pureza, pol e alto teor de fibra e AR (em percentagem de cana). Além disso, independentemente da irrigação, o terceiro corte apresentou menores valores de ATR.

Quanto ao teor de fibra da cana, à medida que se aumentou a dose de vinhaça o teor de fibra diminuiu linearmente (Figura 4), indicando que, para cada $100 \mathrm{~m}^{3}$ de vinhaça que se adiciona espera-se uma retração média de $0,25 \%$ no teor de fibra. Ressalta-se que menores teores de fibras resultam em cana com menos dureza, o que é interessante para os produtores de cachaça de alambique, pelo maior volume de caldo

Tabela 2. Valores médios para as características tecnológicas de cana-de-açúcar, com aplicação de vinhaça e complementação de adubação nitrogenada, no terceiro e quarto cortes, em ambientes com irrigação (Ci3 e Ci4) e sem irrigação (Si3 e Si4) $)^{(1)}$.

\begin{tabular}{lllllll}
\hline Ambientes & \multicolumn{1}{c}{ Brix } & \multicolumn{1}{c}{ Pureza } & $\begin{array}{c}\text { Pol } \\
\text { - }\end{array}$ & Fibra & AR & $\begin{array}{c}\text { ATR } \\
\left(\mathrm{kg} \mathrm{Mg}^{-1}\right)\end{array}$ \\
\hline Ci3 & $17,96 \mathrm{c}$ & $91,26 \mathrm{bc}$ & $16,11 \mathrm{bc}$ & $11,99 \mathrm{a}$ & $0,43 \mathrm{ab}$ & $157,41 \mathrm{~b}$ \\
$\mathrm{Si} 3$ & $17,75 \mathrm{c}$ & $90,55 \mathrm{c}$ & $15,78 \mathrm{c}$ & $11,31 \mathrm{~b}$ & $0,45 \mathrm{a}$ & $154,93 \mathrm{~b}$ \\
$\mathrm{Ci} 4$ & $18,67 \mathrm{a}$ & $92,20 \mathrm{ab}$ & $16,97 \mathrm{a}$ & $10,88 \mathrm{c}$ & $0,39 \mathrm{~b}$ & $165,43 \mathrm{a}$ \\
Si4 & $18,33 \mathrm{ab}$ & $93,04 \mathrm{a}$ & $16,66 \mathrm{ab}$ & $10,95 \mathrm{bc}$ & $0,37 \mathrm{~b}$ & $163,37 \mathrm{a}$ \\
\hline
\end{tabular}

${ }^{(1)}$ Médias seguidas por letras iguais, nas colunas, não diferem entre si pelo teste t, a 5\% de probabilidade. AR, açúcares redutores; ATR, açúcares totais recuperáveis.

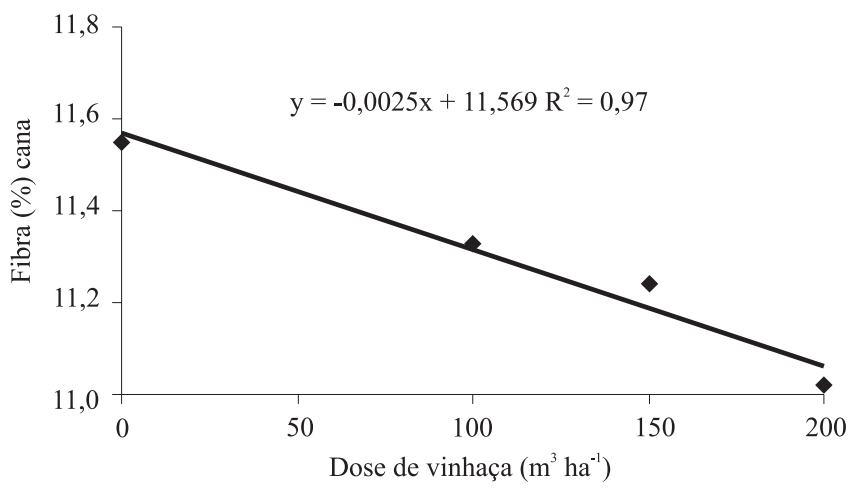

Figura 4. Fibra (\%) cana em função da dose de vinhaça aplicada ao solo.

que se pode extrair de uma mesma quantidade de colmos, com consequente aumento do rendimento final de cachaça. Teor de fibra na cana inferior a $10,5 \%$ é indesejável por causa do balanço energético nas usinas e alambiques, já que é necessário queimar mais bagaço para manter o poder calorífico nas caldeiras. O teor de fibra é muito importante para a manutenção energética das indústrias que processam a cana-de-açúcar, com o teor médio de fibra ideal de 10,5 a 12,5\%. No Estado de São Paulo, segundo Fernandes (2000), o teor de fibras deve estar entre 10 a $11 \%$ para que seja recomendada a industrialização da cana. Neste trabalho, mesmo na maior dose aplicada de vinhaça $\left(200 \mathrm{~m}^{3} \mathrm{ha}^{-1}\right)$, observou-se teor de fibra $(11,02 \%)$ superior ao mínimo recomendado pelo autor.

De modo geral, excetuando-se o teor de fibras, a aplicação de doses crescentes de vinhaça, complementada ou não com nitrogênio, não afetou as características tecnológicas e o ATR da matéria prima industrial. Os valores médios obtidos estão próximos aos reportados por Bernardes \& Câmara (2001), Quintela et al. (2002), Tasso Júnior et al. (2007), Farias et al. (2008) e Leite et al. (2008).

\section{Conclusões}

1. Em cana-de-açúcar de terceiro e quarto corte, há resposta da produtividade de colmos à aplicação de vinhaça de alambique, tanto no ambiente irrigado quanto no não irrigado.

2. A aplicação de doses crescentes de vinhaça proporciona redução no teor de fibra da cana-de-açúcar. 
3. A aplicação de nitrogênio tem efeito sinérgico ao da aplicação de vinhaça, tanto no ambiente irrigado quanto no não irrigado.

4. O uso da irrigação é tecnicamente viável em cana-soca.

\section{Agradecimentos}

À Fundação de Amparo a Pesquisa do Estado de Minas Gerais, pelo fomento à pesquisa; e a Cachaçaria João Mendes que cedeu a estrutura necessária para a instalação do experimento de campo, bem como pelas facilidades oferecidas durante a condução dos trabalhos.

\section{Referências}

BERNARDES, M.S.; CÂMARA, G.M.S. Cultura da cana-de-açúcar. Piracicaba: ESALQ, 2001. 20p.

DANTAS NETO, J.; FIGUEREDO, J.L. da C.; FARIAS, C.H. de A.; AZEVEDO, H.M. de.; AZEVEDO, C.A.V. de. Resposta da cana de açúcar, primeira soca, a níveis de irrigação e adubação de cobertura. Revista Brasileira de Engenharia Agrícola e Ambiental, v.10, p.283-288, 2006.

DOORENBOS, J.; KASSAN, A.H. Efectos del agua sobre el rendimiento de los cultivos. Roma: FAO, 1979. 212p.

FARIAS, C.H. de A.; FERNANDES, P.D.; AZEVEDO, H.M.; DANTAS NETO, J. Índices de crescimento da cana-de-açúcar irrigada e de sequeiro no Estado da Paraíba. Revista Brasileira de Engenharia Agrícola e Ambiental, v.12, p.356-362, 2008.

FERNANDES, A.C. Cálculos na agroindústria da cana-de-açúcar. Stab: Açúcar, Álcool e Subprodutos, v.11, p.55-65, 2000.

FREIRE, W.J.; CORTEZ, L.A.B. Vinhaça de cana-de-açúcar. Guaíba: Agropecuária, 2000. 203 p.

GOMES, F.P. Curso de estatística experimental. 14.ed. Piracicaba: ESALQ, 2000. 477p.

KORNDORFER, G.H.; RIBEIRO, A.C.; ANDRADE, L.A. de B. Cana-de-açúcar. In: RIBEIRO, A.C.; GUIMARÃES, P.T.G.; ALVAREZ V., V.H. (Ed.). Recomendações para o uso de corretivos e fertilizantes em minas gerais: 5a aproximação. Viçosa: UFV, 1999. p.285-288.

LEITE, G.M.V.; ANDRADE, L.A.B de.; GARCIA, J.C.; ANJOS, I.A. dos. Efeitos de fontes e doses de silicato de cálcio no rendimento agrícola e na qualidade tecnológica da cana-de-açúcar, cultivar sp80-1816. Ciência e Agrotecnologia, v.32, p.1120-1125, 2008.
MATIOLI, C.S.; BARCELOS, J. Irrigação suplementar de cana-de-açúcar: modelo de análise de decisão para a região norte do Estado de São Paulo. Stab: Açúcar, Álcool e Subprodutos, v.17, p.42-45, 1999.

MINAS GERAIS. Deliberação normativa ${ }^{\circ} 12$, de 16 de dezembro de 1986. Estabelece normas e padrões para emissões de poluentes na atmosfera dá outras providências. Diário do Executivo [de] Minas Gerais, 10 jan. 1987.

NOGUEIRA, A.M.P.; VENTURINI FILHO, W.G. Aguardente de cana. Botucatu: UNESP, 2005. 71p.

PAULINO,A.F.; MEDINA, C. de C.; ROBAINA, C.R.P.; LAURANI, R.A. Produções agrícola e industrial de cana-de-açúcar submetida a doses de vinhaça. Ciências Agrárias, v.23, p.145-150, 2002.

QUINTELA, A.C.R.; ANDRADE, L.A. de B.; CORRÊA, J.B.D.; REZENDE, P.M. Controle de plantas daninhas em cana crua (cultivar RB83-5089) no sistema integrado palhiço, herbicida e vinhaça. STAB: Açúcar Álcool e Subprodutos, v.20, p.38-42, 2002.

RESENDE, A.S. de; SANTOS, A.; XAVIER, R.P.; COELHO, C.H.; GONDIM, A.; OLIVEIRA, O.C.; ALVES, B.J.R.; BODDEY, R.M.; URQUIAGA, S. Efeito da queima da palhada da cana-de-açúcar e de aplicações de vinhaça e adubo nitrogenado nas características tecnológicas da cultura. Revista Brasileira de Ciência do Solo, v.30, p.937-941, 2006.

RODRIGUES, J.C.S.; PENA, M.J.; MORAES, R.S. Complementação nitrogenada em áreas fertilizadas com vinhaça. In: REUNIÃO TÉCNICA AGRONÔMICA: MANEJO E ADUBAÇÃO NA CULTURA DA CANA-DE-AÇÚCAR, 3., 1984, Piracicaba. Anais. Piracicaba: COPERSUCAR, 1984. p.180-195.

SANTOS, M.A.L dos.; FRIZZONE, J.A. Irrigação suplementar da cana de açúcar (Saccharum spp): um modelo de análise de decisão para o Estado de Alagoas. Irriga, v.11, p.339-355, 2006.

SIQUEIRA, M.L. Influência da taxa de carregamento orgânico na degradação anaeróbia da vinhaça em reator de leito fluidizado. 2008. 151p. Dissertação (Mestrado) - Universidade Federal de São Carlos, São Carlos.

TASSO JÚNIOR, L.C.; MARQUES, M.O.; FRANCO, A.; NOGUEIRA, G. de A.; NOBILE, F.O. de.; CAMILOTTI, F.; SILVA, A.R. da. Produtividade e qualidade de cana-de-açúcar cultivada em solo tratado com lodo de esgoto, vinhaça e adubos minerais. Engenharia Agrícola, v.27, p.276-283, 2007.

TRIVELIN, P.C.O.; VICTORIA, R.L.; RODRIGUES, J.C.S. Aproveitamento por soqueira de cana-de-açúcar de final de safra do nitrogênio da aquamônia- $-{ }^{15} \mathrm{~N}$ e uréia $-{ }^{15} \mathrm{~N}$ aplicado ao solo em complemento à vinhaça. Pesquisa Agropecuária Brasileira, v.30, p.1375-1385, 1995.

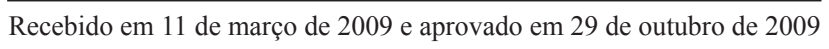

